\title{
Transcriptome analysis of Anastrepha fraterculus sp. 1 males, females, and embryos: insights into development, courtship, and reproduction
}

Alejandra Carla Scannapieco ${ }^{1}$, Claudia Alejandra Conte ${ }^{1}$, Máximo Rivarola², Juan Pedro Wulff', Irina Muntaabski', Andrés Ribone ${ }^{2}$, Fabián Milla', Jorge Luis Cladera' and Silvia Beatriz Lanzavecchia ${ }^{1 *}$

\begin{abstract}
Background: Anastrepha fraterculus sp. 1 is considered a quarantine pest in several American countries. Since chemical control applied in an integrated pest management program is the only strategy utilized against this pest, the development of pesticide-free methods, such as the Sterile Insect Technique, is being considered. The search for genes involved in sex-determination and differentiation, and in metabolic pathways associated with communication and mating behaviour, contributes with key information to the development of genetic control strategies. The aims of this work were to perform a comprehensive analysis of A. fraterculus sp. 1 transcriptome and to obtain an initial evaluation of genes associated with main metabolic pathways by the expression analysis of specific transcripts identified in embryos and adults.

Results: Sexually mature adults of both sexes and $72 \mathrm{~h}$ embryos were considered for transcriptome analysis. The de novo transcriptome assembly was fairly complete (62.9\% complete BUSCO orthologs detected) with a total of 86 , 925 transcripts assembled and 28,756 GO annotated sequences. Paired-comparisons between libraries showed 319 transcripts differently expressed between embryos and females, 1242 between embryos and males, and 464 between sexes. Using this information and genes searches based on published studies from other tephritid species, we evaluated a set of transcripts involved in development, courtship and metabolic pathways. The qPCR analysis evidenced that the early genes serendipity alpha and transformer-2 displayed similar expression levels in the analyzed stages, while heat shock protein 27 is over-expressed in embryos and females in comparison to males. The expression of genes associated with courtship (takeout-like, odorant-binding protein 50a1) differed between males and females, independently of their reproductive status (virgin vs mated individuals). Genes associated with metabolic pathways (maltase 2-like, androgen-induced gene 1) showed differential expression between embryos and adults. Furthermore, 14,262 microsatellite motifs were identified, with 11,208 transcripts containing at least one (Continued on next page)
\end{abstract}

\footnotetext{
* Correspondence: lanzavecchia.silvia@inta.gob.ar

"Instituto de Genética "E. A. Favret" (IGEAF) gv Instituto de Agrobiotecnología y Biología Molecular (IABIMO), Instituo Nacional de Tecnología Agropecuaria (INTA) - Consejo de Investigaciones Científicas y Técnicas (CONICET), Hurlingham, Buenos Aires, Argentina

Full list of author information is available at the end of the article
} 
(Continued from previous page)

simple sequence repeat, including $48 \%$ of di/trinucleotide motifs.

Conclusion: Our results significantly expand the available gene space of $A$. fraterculus sp. 1, contributing with a fairly complete transcript database of embryos and adults. The expression analysis of the selected candidate genes, along with a set of microsatellite markers, provides a valuable resource for further genetic characterization of A. fraterculus sp. 1 and supports the development of specific genetic control strategies.

Keywords: Fruit fly, RNA-Seq analysis, Transcript annotation, Differential gene expression, Microsatellite markers

\section{Background}

The South American fruit fly, Anastrepha fraterculus Wiedemann (Diptera: Tephritidae), is considered one of the most economically important pest species in several American countries. This species has broad geographical distribution and a wide host range, attacking at least 110 host plant species including major fruit crops [1-5]. Its presence limits international trade because of quarantine regulations to avoid cross-border introductions [6-8]. Although A. fraterculus is currently considered a complex of cryptic species [9-12], only one biological entity, named A. fraterculus sp. 1 [10] or Brazilian 1 morphotype [11], has been detected in Argentina and southern Brazil.

The most effective control measure against tephritid pests is the Sterile Insect Technique (SIT), in which flies are mass-reared, sterilized by radiation, and released into the wild where they mate with fertile individuals, subsequently laying unfertilized eggs, thereby reducing the pest population size $[13,14]$. SIT has been successfully used in eradication programs against the Mediterranean fruit fly Ceratitis capitata [15], Bactrocera dorsalis and other Bactrocera species [16]. Also, it is currently being applied against Anastrepha ludens, and A. obligua [17-19]. However, only chemical approaches have been used to control A. fraterculus populations in the field to date [20].

The implementation of efficient procedures of sexing and sterilization during mass rearing is of importance for an effective SIT application. In particular, the physical sexing mechanisms for male and female separation (genetic sexing strain - GSS) are necessary to produce and release only males and thus avoid the costs of female rearing, mating competition, and oviposition damage to host plants, difficulties observed when bisexual strains were applied by SIT [19, 21, 22]. The GSS has been developed using classical approaches for several species of fruit flies, such as A. ludens $[19,23], B$. dorsalis [24], C. capitata [25, 26], and Zeugodacus cucurbitae [27]. In A. fraterculus, six pupal colour-based GSS strains have been developed and are currently under evaluation at the IAEA Insect Pest Control Laboratory [28].

In addition to these developments, genes involved in the sex determination pathways have been described for A. fraterculus. For example, those belonging to the primary sex-determining cascade, such as transformer [29], transformer-2 [30] and doublesex [31] have been studied in A. obliqua and $A$. fraterculus, providing valuable information to improve the existing $A$. fraterculus GSS strains generated by the traditional approach. Furthermore, this knowledge lays the molecular basis to develop GSS in this species by insect genetic engineering systems such as transgenesis and CRISPR Cas9 techniques, successfully utilized in other Tephritid species $([32,33]$ and references therein).

The study of the molecular mechanisms underlying the physiological processes involved in communication, courtship, and reproduction is also essential for the development of SIT approaches, including the efficient mass rearing of the insect pest species, and the competitiveness of sterile individuals in the field. For example, mating can induce profound physiological changes and behavioural switches in females, including changes in oviposition patterns, mating refractoriness, and longevity [34-36] which have practical consequences for SIT success. Furthermore, mating success is strongly associated with communication among individuals and the detection of volatile phytochemicals [37, 38]. These volatiles affect the behaviour and physiology of phytophagous insect species and are key components of the mating competitiveness of A. fraterculus males in the field [39-41]. Recent studies have utilized a transcriptome approach to identify and differentiate physiological aspects of Anastrepha species [42] and deepen the knowledge of the molecular mechanisms involved in olfaction [43-45] and cell processes [46, 47].

In the present study, we performed a full transcriptome analysis of $A$. fraterculus sp. 1 in $72 \mathrm{~h}$ embryos and adults to contribute to a fairly complete sequence database of this species. Using our de novo GO annotation, specific gene searches and a strict filtering of transcripts by their expression profiles, we selected putative transcripts involved in development, courtship and metabolic pathways and analyzed their expression by qPCR in embryos, as well as virgin and mated adults. Furthermore, we identified microsatellite motifs to augment the set of available molecular markers of this species to monitor the pest in the field. 


\section{Results}

\section{Sequencing and annotation}

The RNA-Seq analysis of the three libraries $(72 \mathrm{~h} \mathrm{em-}$ bryos, adult virgin females and adult virgin males) from A. fraterculus sp. 1 yielded an average of 5,535,000 reads per library, with a mean read length of 151 base pairs (bp) and a low percentage of discarded sequences (< $0.14 \%$; Table 1). A total of 86,925 assembled sequences showed an average length of $682 \mathrm{bp}$ (ranging between 200 and 12,700 bp). A BLASTX search (Expected Value cut off: 1.0x10E-10; Number Blast Hits retrieved: 10; Default scoring matrix: Blossum62) against the complete NR database of NCBI was performed to characterize all the assembled transcripts. A total of 52,655 transcripts had at least one hit (Table 1). Overall, we obtained a total of 471,646 BLAST hits against our A. fraterculus sp. 1 transcriptome and evidenced that the most highly represented species (showing the highest number of hits) was C. capitata (18.6\% of BLAST hits) followed by $Z$. cucurbitae (previously known as Bactrocera cucurbitae) (16.7\%) and by B. dorsalis (14.1\%). Conversely, when only the top BLAST hit was analyzed (a total of 52,665 hits), B. dorsalis appeared in the first position with 18, 642 hits, followed by Z. cucurbitae (16,823 hits) and $C$. capitata (15,333 hits).

Table 1 Summary of the A. fraterculus sp. 1 transcriptome

\begin{tabular}{ll}
\hline Total number of reads (72 h embryos/ Adult & $5,519,495 / 4,765,195 /$ \\
females/ Adult males) & $6,322,876$ \\
Number of discarded reads (72 h embryos/ & $6640 / 6653 / 6356$ \\
Adult females/ Adult males) & \\
Mean read length (bp) & 151 \\
Smallest transcript length (bp) & 201 \\
Number of largest transcript length (bp) & 12,701 \\
Number of overall average length (bp) & 682.8 \\
Median transcript length (bp) & 410 \\
N50 (bp) & 1020 \\
Total assembled sequences & 86,925 \\
Number of loci & 57,000 \\
Number of GO annotated sequences & 28,756 \\
Number of BLAST annotated sequences & 52,655 \\
GC\% (72 h embryos/ Adult females/ & $44 / 44 / 42$ \\
Adult males) & \\
Complete BUSCOs ${ }^{a}$ & 1762 (62.9\%) \\
Complete and single-copy BUSCOs ${ }^{\text {a }}$ & $827(29.5)$ \\
Complete and duplicated BUSCOs ${ }^{a}$ & 935 (33.4\%) \\
Fragmented BUSCOs ${ }^{\text {a }}$ & $484(17.3 \%)$ \\
Missing BUSCOs ${ }^{a}$ & $553(19.8 \%)$ \\
\hline
\end{tabular}

${ }^{\mathrm{a}} \mathrm{BUSCO}$ completeness assessment results for $A$. fraterculus transcriptome. Results are based on a complete set out of 2799 single-copy orthologs. $b p$ base pairs
Gene Ontology assignment yielded 28,756 GO annotated transcripts (Fig. 1). The distribution of $A$. fraterculussp. 1 annotated sequences in the three main categories showed 23,864 sequences within Molecular Function (GO: 0003674), 23,501 sequences in Biological Process (GO: 0008150), and 15,980 transcripts in Cellular Component (GO: 0005575). The major GO terms within the Molecular Function category were "binding" (GO: 0005488; 14,921 transcripts; 51.9\%) and "catalytic activity" (GO: 0003824; 14,353 transcripts; 49.9\%). For the Biological Process category, "cellular process" (GO: 0009987; 15,910 transcripts; 55.3\%) and "metabolic process" (GO: 0008152; 16,513 transcripts; 57.4\%) were the most highly represented subcategories. In the case of the Cellular Component category, "cell" (GO: 0005623) was the most highly represented subcategory with 12 , 284 transcripts $(42.7 \%)$ (Fig. 1). In addition, the most highly represented subcategories (the third GO level) were obtained (Additional File 1) including main terms involved in biological processes, development, behaviour, and reproduction (Additional File 2).

\section{Ortholog prediction and quality of $A$. fraterculus transcriptome}

The BUSCO analysis was performed to evaluate the completeness of our transcriptome. We recovered 62.9\% of the complete orthologs from the BUSCO Diptera dataset with approximately $20 \%$ of these orthologs missing in our assembly (Table 1). Some of the missing orthologs are probably an indication of an incomplete transcriptome assembly, while others are possibly due to extremely low levels of expression in our experimental design. To further inspect and compare our assembly (INTA), we downloaded and ran a de novo assembly adding an RNA-Seq dataset from the USDA-ARS (extracted from the same $A$. fraterculus morphotype and with a similar experimental design; NCBI BioBroject: PRJNA338343). The USDA-INTA de novo assembly performed similarly in terms of BUSCO ortholog detection (70\% recovered), but poorly in terms of the new assembled transcripts, retrieving at least one BLASTX hit per sequence. Only $47.2 \%$ of USDA-INTA transcripts gave BLASTX hits, while $60.7 \%$ of INTA transcripts gave at least one hit. Furthermore, GO annotations from the BLASTX hits of USDA-INTA transcripts resulted in only $1.7 \%$ of transcripts with at least one GO annotation (Blast2GO), when compared to 55\% from INTA assembled transcripts. According with these comparative results, we continued the data analysis using the INTA transcriptome assembly.

In addition to the BUSCO analysis, which uses nucleotide transcriptome data, a deeper evaluation into closely related species proteomes was performed. Specifically, all open reading frames (ORFs) were predicted 




Fig. 1 Gene Ontology (GO) assignment of A. fraterculus sp. 1 transcripts. The results are summarized in the three main categories "cellular component", "molecular function" and "biological process". GO was assigned to 28,756 transcripts in total. The percentage (left Y-axis) and total number (right Y-axis) of transcripts in each category (the second GO level) are shown. Y-axes are in log (10) scale. WEGO was used to produce the graph

regardless of BLASTX hits to NR DB. An in silico analysis using Transdecoder software resulted in the detection of 38,933 putative proteins with at least 100 amino acids. We identified ortholog groups by inter-specific pairwise comparisons (OrthoMCL) considering all predicted proteins of three closely related species $[48,49]$ with available and fully annotated genomes (RefSeq DB NCBI) and 18S rRNA complete gene sequence (BLASTN search; > $80 \%$ query coverage and the highest percentage of identity): B. oleae [PRJNA 293367/288990], Rhagoletis zephyria [PRJNA331175/321204], and C. capitata [PRJNA201381] (Additional File 3). The number of predicted orthologs in the 2-way paired analysis by OrthoMCL showed a similar number of ortholog proteins present in each comparison (Table 2). In addition, we identified the number of orthologs present in two, three, and four proteomes of closely related species, and found a similar trend of orthologs present in each comparison (Additional File 4). These results suggest that the reconstruction of the obtained transcriptome is fairly complete in comparison to closely related species with assembled genomes. Furthermore, BUSCO analysis showed $33.4 \%$ of complete and duplicated transcripts (Table 1), indicating that our transcriptome data are somewhat redundant.

\section{Differential expression analysis between libraries}

Paired-comparisons between libraries were performed by $\mathrm{DE}$ analysis (EdgeR) considering only transcripts with more than 10 counts per million $(\mathrm{cpm}>10)$ in at least two of the three samples. The Biological Coefficient of Variation (bcv) was set at 0.4, a value recommended by EdgeR [50] for comparing RNA samples of different conditions without replicates. We obtained 7188 differentially expressed transcripts in the $72 \mathrm{~h}$ embryo/ female comparison, 15,752 transcripts in $72 \mathrm{~h}$ embryo/ male comparison, and 7453 sequences between adults (female/ male comparison) (Additional File 5). Based on this database of differentially expressed transcripts, a subsequent manual filtering (threshold criterion of 10 fold-change [FC $>10$ for over-expression] and 0.1 fold- 
Table 2 Ortholog prediction analysis for the A. fraterculus sp. 1 transcriptome compared to three closely related species (B. oleae and R. zephyria and C. capitata) (Additional File 3). The table shows the number of sequences (predicted proteins) from each species with orthologs in every other proteome

\begin{tabular}{|c|c|c|c|c|c|}
\hline & & \multicolumn{4}{|c|}{$\ldots$ with orthologs in ... } \\
\hline & & A. fraterculus & B. oleae & R. zephyria & C. capitatc \\
\hline \multirow[t]{4}{*}{ Number of proteins from . } & A. fraterculus & & 16,420 & 16,931 & 16,508 \\
\hline & B. oleae & 12,627 & & 15,444 & 16,047 \\
\hline & R. zephyria & 15,289 & 19,023 & & 19,664 \\
\hline & C. capitata & 15,205 & 20,057 & 19,413 & \\
\hline
\end{tabular}

change $[\mathrm{FC}<0.1$ for under-expression]) was performed. Results showed 319 differentially expressed transcripts in the $72 \mathrm{~h}$ embryo/ female comparison, 1242 transcripts in the $72 \mathrm{~h}$ embryo/male comparison, and 464 transcripts between females and males (Fig. 2; Additional File 6 A and B).

\section{Selection of transcripts for qPCR assay}

Based on the information of the differentially expressed transcripts among libraries (Fig. 2; Additional File 6 A and $B$ ) and their predicted functions (GO annotation or the best BLAST hits), a selection was performed in order to identify those transcripts potentially associated to development, reproduction, courtship and communication in the $A$. fraterculus sp. 1 transcriptome. We detected transcripts annotated as heat shock proteins ( $h s p 23$, $h s p 27$ and $h s p 70)$, odorant-binding proteins (obp1, obp19 and obp99), and transcripts associated to female and male physiology (Additional File 7 A).
Our transcriptome was also screened for genes previously reported in the literature associated to early development and sex determination. This screening revealed the presence of several transcripts with a high similitude to early developmental genes, such as serendipity alpha and slow-as-molasses and to genes of the sex determination cascade (transformer, transformer 2, doublesex) (Additional File 7 B). In addition, we detected transcripts with high similarity to odorant-binding protein genes (odorant-binding protein 49 and odorant-binding protein 50a1) previously described for $A$. fraterculus by Campanini et al. [45] (Additional File 7 B).

To perform a final selection of transcripts to be evaluated by qPCR, we filtered the transcripts from Additional File 7 (A and B) database by the unambiguous identification of the transcript (e.g. unique transcript sequence associated to a particular annotated gene without potential isoforms or with identifiable gene variants



Egg/Female

Egg/Male

Female/Male

Fig. 2 Descriptive analysis of differentially expressed transcripts in paired-comparisons between libraries. Values inside each bar indicate the number of differentially expressed transcripts ( $Y$-axis) for each comparison ( $72 \mathrm{~h}$ embryo/ female, $72 \mathrm{~h}$ embryos/ male, female/ male). $\mathbf{7 2} \mathbf{~ h}$ embryos/ females: the number of transcripts over or under expressed in $72 \mathrm{~h}$ embryos compared to females. $\mathbf{7 2} \mathbf{h}$ embryos/ males: the number of transcripts over or under expressed in $72 \mathrm{~h}$ embryos compared to males. Females/ males: the number of transcripts over or under expressed in females compared to males. Threshold criteria: from the transcriptome assembly only transcripts with $>10 \mathrm{cpm}$ were considered; FC $>10$ over-represented transcripts; FC $<0.1$ under-represented transcripts 
Table 3 Description, annotation and GPCR characteristics of selected transcripts

\begin{tabular}{|c|c|c|c|c|c|}
\hline ID/ gene name ${ }^{a}$ & $\begin{array}{l}\text { GO term } \\
\text { assigned }\end{array}$ & Accession no. ${ }^{b}$ & Primer sequence $5^{\prime}-3^{\prime}$ & $\begin{array}{l}\text { Product } \\
\text { size (bp) }\end{array}$ & $\begin{array}{l}\text { qPCR } \\
\text { efficiency }\end{array}$ \\
\hline \multicolumn{6}{|l|}{ Development } \\
\hline Trinity DN12595_c0_g1_i2/ serendipity alpha & $\begin{array}{l}0016020 / \\
0007349 / \\
0005737\end{array}$ & JQ599256 & $\begin{array}{l}\text { Fw: TGAGAGTTTGCGCACAGTGA } \\
\text { Rv: CACTGCTGCACCTGAGTCAT }\end{array}$ & 154 & 1.882 \\
\hline Trinity DN15480_c0_g1_i3/transformer-2 & - & KY204955 & $\begin{array}{l}\text { Fw: TGGAAATCGATGATCGCCGT } \\
\text { Rv: GACGACGGGAGCGATAATCA }\end{array}$ & 144 & 1.957 \\
\hline $\begin{array}{l}\text { Trinity DN10186_c0_g1_i4/ heat shock } \\
\text { protein } 27\end{array}$ & $\begin{array}{l}0005875 / \\
0008340 / \\
0042026 / \\
0042595\end{array}$ & XM011197636 & $\begin{array}{l}\text { Fw: TTCGGCTTGGGCTTGCATC } \\
\text { Rv: TGCACACTTGGAAGCCATCT }\end{array}$ & 200 & 1.929 \\
\hline \multicolumn{6}{|l|}{ Courtship behavior/communication } \\
\hline Trinity DN11516_c0_g1_i3/takeout-like & - & JQ048622 & $\begin{array}{l}\text { Fw: TTACGGCGTTGGTAGTGCC } \\
\text { Rv: CCGATCAACTCAGCTTTGGG }\end{array}$ & 106 & 1.924 \\
\hline $\begin{array}{l}\text { Trinity DN1 1027_c0_g1_i1/ odorant-binding } \\
\text { protein 50a1 }\end{array}$ & - & KU317977 & $\begin{array}{l}\text { Fw: GCTGCAGTCGTTGTCCATTG } \\
\text { Rv: GTGTCGACATGCAACTCAGC }\end{array}$ & 85 & 1.934 \\
\hline \multicolumn{6}{|l|}{ Physiological pathways } \\
\hline $\begin{array}{l}\text { Trinity DN15916_c0_g4_i3/androgen-induced } \\
\text { gene } 1 \text { protein }\end{array}$ & $\begin{array}{l}0012505 / \\
0016021\end{array}$ & XM029042282 & $\begin{array}{l}\text { Fw: GCGTGTTGGATGCAGTGTTा } \\
\text { Rv: CGTTTGGGATAGGCACGGAA }\end{array}$ & 109 & 1.905 \\
\hline Trinity DN12527_c0_g1_i1/ maltase 2-like & - & XM011180327 & $\begin{array}{l}\text { Fw: CCAGCCCGAATACGGTACAA } \\
\text { Rv: CGGTCGACGGACTTCTGAAA }\end{array}$ & 138 & 1.907 \\
\hline \multicolumn{6}{|l|}{ Reference genes } \\
\hline $\begin{array}{l}\text { Trinity DN6544_c0_g1_i2/ribosomal } \\
\text { protein L18 }\end{array}$ & $\begin{array}{l}0000022 / \\
0003735 / \\
0022625 / \\
0006412\end{array}$ & NM139834 & $\begin{array}{l}\text { Fw: GAAAGGCTCCTGGTGTTCCA } \\
\text { Rv: TTTGTAACCGCAGCTTGACC }\end{array}$ & 104 & 1.963 \\
\hline $\begin{array}{l}\text { Trinity DN12142_c0_g1_i2/ elongation } \\
\text { factor - } 1 a\end{array}$ & $\begin{array}{l}0008340 / \\
0003746 / \\
0006414 / \\
0005525 / \\
0006184 / \\
0005829 / \\
0005853\end{array}$ & GU339154 & $\begin{array}{l}\text { Fw: GCACCACGAAGCTTAGCAG } \\
\text { Rv: ACTGGAGTGTAACCGTTGGC }\end{array}$ & 198 & 1.959 \\
\hline
\end{tabular}

a Gene name from the best BLAST hit or GO annotation

${ }^{b}$ Accession number from the annotated sequence with the best BLAST hit

for the univocal analysis of its expression profile) (Table 3).

\section{Expression analysis of candidate genes}

The expression levels of the seven candidate transcripts and the two reference genes (Table 3) were evaluated by means of qPCR to validate the RNA-Seq expression data. Our results showed a highly significant positive correlation between RNA-Seq and qPCR datasets in each paired-comparison: embryos/virgin female (Spearman Correlation; $\mathrm{r}=0.87 ; P<0.0001$ ); embryos/ virgin male (Spearman Correlation; $\mathrm{r}=0.93 ; P<0.0001)$; and virgin male/ virgin female (Spearman Correlation; $\mathrm{r}=0.87 ; \quad P<0.0001$ ) (Additional File 8).

The expression profiles obtained by qPCR evidenced an over-expression in embryos and females compared to males for the transcript annotated as heat shock protein 27, as we expected. Conversely, serendipity alpha and transformer-2 transcripts were equally expressed in the compared treatments $(72 \mathrm{~h}$ embryos; sexually mature virgin females and males) (Fig. 3). Significant differences in gene expression were detected for transcripts annotated as takeout-like and odorant-binding protein 50a1 between all compared treatments (Fig. 3). Specifically, takeout-like and odorant-binding protein 50a1 were under-expressed in embryos, compared to adults. Males showed a higher expression level than females in the case of takeout-like, and the opposite pattern was found for odorant-binding protein 50a1. The results of maltase 2-like transcript evidenced an over-expression in embryos relative to adults and in females relative to males (Fig. 3). Conversely, males evidenced greater levels of androgen-induced gene 1 protein in comparison to embryos and females, but the difference between sexes was only marginally significant ( $P=0.08$; Fig. 3 ).

The expression levels of most of the analyzed transcripts (except for serendipity alpha, which was not evaluated in this case) were similar between virgin and 

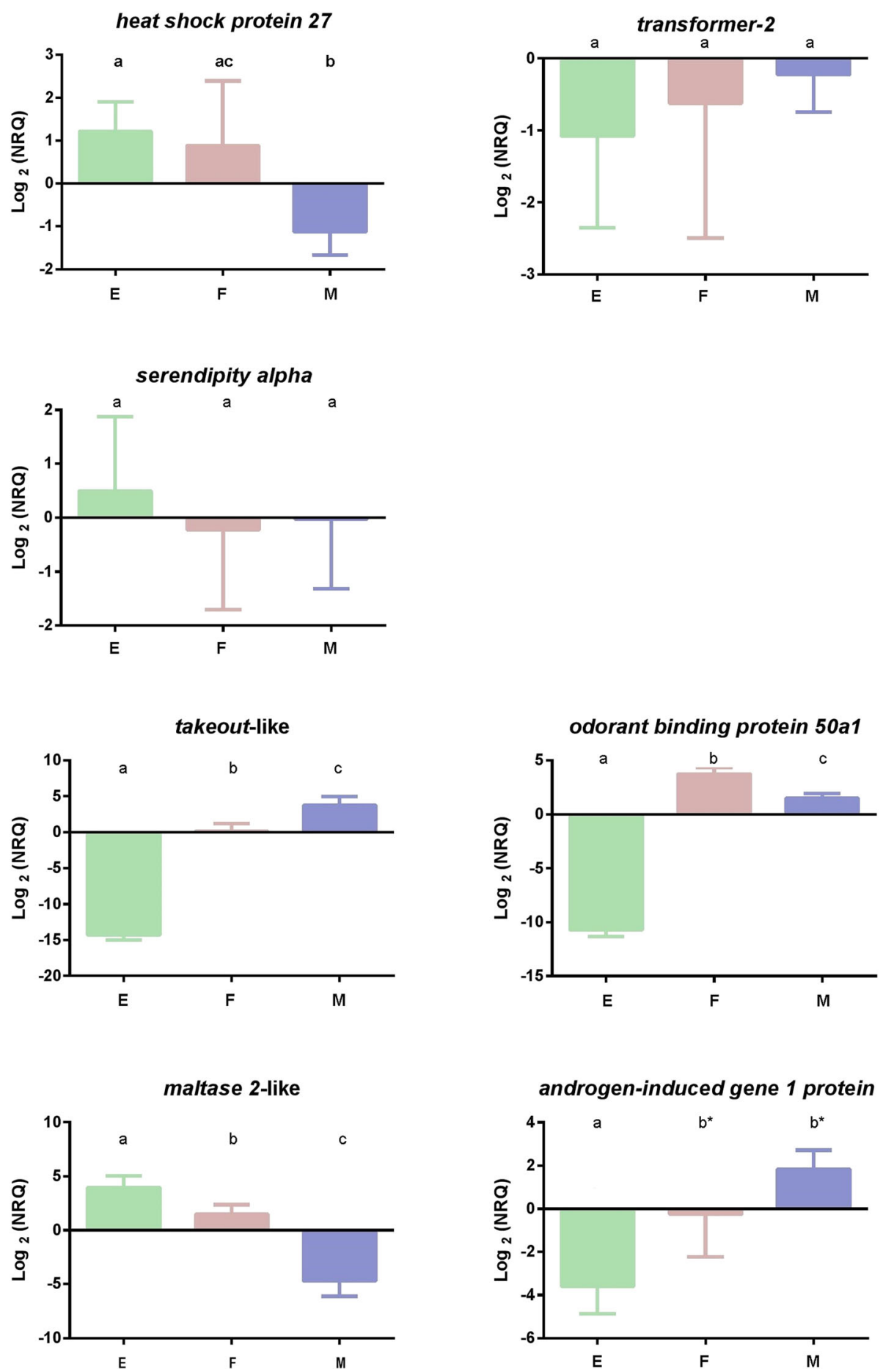

Fig. 3 Comparative expression profiles of candidate genes obtained by qPCR among $E$ ( $72 \mathrm{~h}$ embryos), sexually mature and virgin adults females (F) and males (M). NRQ are Expression Units. Different letters indicate significant differences $(P<0.05)$ between stages (t-test results). Letters marked with an asterisk $\left(^{*}\right)$ showed statistically marginal differences $(P=0.08)$. Reference genes for qPCR: ribosomal protein L 18 ( $\left.r p L 18\right)$ and elongation factor-1a (ef-1a)

mated adults (Fig. 4). In particular, the expression levels of transformer-2 and odorant-binding protein $50 a 1$ were higher in mated than virgin females and males, respectively (Fig. 4).
Genetic diversity: prediction of molecular markers

After analyzing 86,925 sequences, we identified 12,956 simple sequence repeat (SSRs or microsatellites) motifs in the $A$. fraterculus sp. 1 transcriptome as potential 
heat shock protein 27

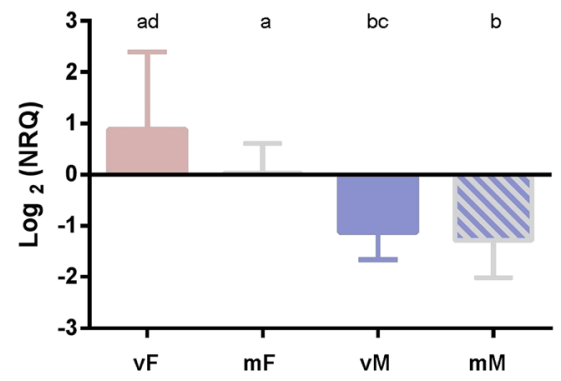

takeout-like

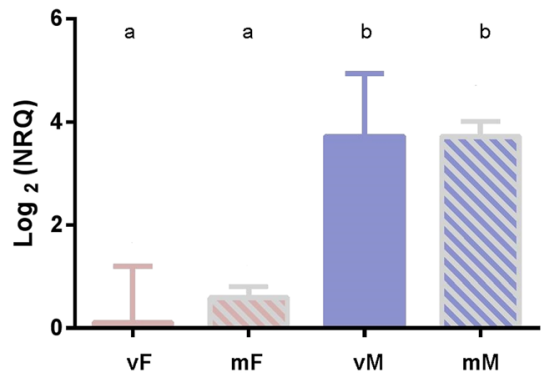

maltase 2-like

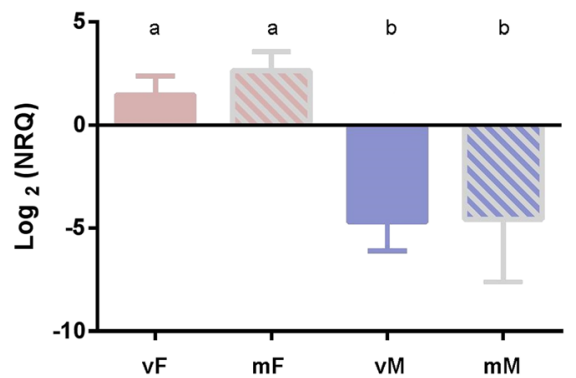

transformer-2

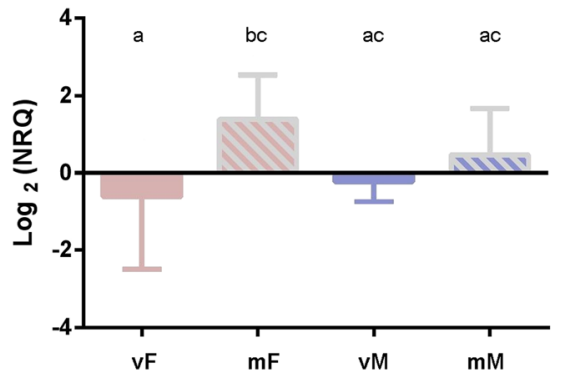

odorant binding protein 50a1

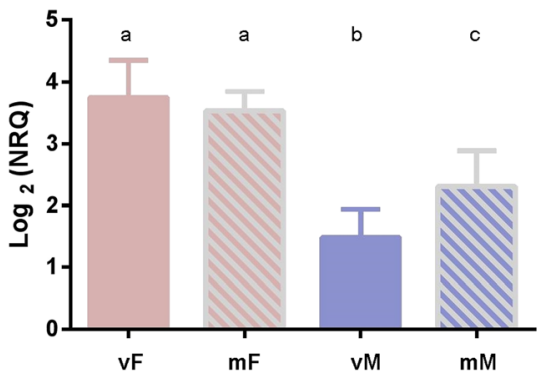

androgen-induced gene 1 protein

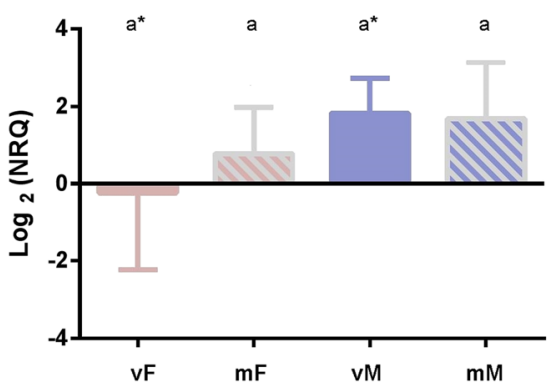

Fig. 4 Comparative expression profiles of candidate genes obtained by qPCR among virgin vs mated females ( $v F$, $m F$ ) and $m a l e s(v M, m M)$. NRQ are Expression Units. Different letters indicate significant differences $(P<0.05)$ between treatments (t-test results). Letters marked with an asterisk ${ }^{*}$ ) showed statistically marginal differences $(P=0.08)$. Reference genes for qPCR: ribosomal protein L18 (rpL18) and elongation factor-1a (ef-1a)

molecular markers for this species. We detected 11,208 transcripts with at least one SSR motif and 2216 sequences with more than one SSR. In addition, 1306 SSRs were found in compound formation (including at least two different types of microsatellite motif) (Additional File 9). The most frequent type of microsatellite corresponded to tetranucleotide $(40 \%)$, dinucleotide $(24 \%)$ and trinucleotide (24\%) repeats, with penta and hexanucleotide motifs (5 and $6 \%$, respectively) being less abundant (Fig. 5a; Additional File 9).

The most frequent combinations for tetranucleotide motifs were TATG/CATA (12.4\%) and ATAG/CTAT (8.4\%); AT/AT (18.5\%) and AC/GT (17.3\%) for dinucleotide motif and CAA/TTG (12.9\%) and CAG/CTG (7.8\%) for trinucleotide repeats (Fig. 5b and c; Additional File 9). In addition, we performed in silico PCRs on all
SRRs using the assembled transcriptome (in-house script). We obtained 10,968 SSRs (84.7\%) that had adequate flanking sequences to allow the design of appropriate unique primers (Additional File 10).

\section{Discussion}

In this study, we performed a comprehensive transcriptome analysis of $A$. fraterculus sp. 1 and utilized a bioinformatic approach to identify differentially expressed genes among males, females and embryos. We validated the in silico information by $\mathrm{qPCR}$ and compared the expression level of several candidate genes associated with development, communication and reproduction.

The transcriptome assembly showed 52,655 BLAST annotated transcripts and 28,756 sequences with an assigned GO term. BLASTX results showed a high number of hits 




Fig. 5 Microsatellite marker prediction. a Distribution of microsatellite motif by repeat type classes. Numbers represent percentage of transcripts within each repeat class (2: di-, 3: tri-, 4: tetra- and 5: pentanucleotide motifs, respectively). b Distribution and composition of di-nucleotide repeats. c Distribution and composition of tri-nucleotide repeats with $C$. capitata, the best-annotated tephritid species, probably reflecting the presence of high quality and quantity of annotated sequences available on NCBI databases for this species. Conversely, when top BLAST hits were considered, $B$. dorsalis appeared as the most highly represented species, showing a considerable number of annotated sequences registered in the NCBI databases and a close phylogenetic relationship with the species under study. A gene ontology assessment revealed a good representation of GO terms in our transcriptome related to developmental process, behaviour and reproduction.

The analysis of predicted orthologs showed that the $A$. fraterculus sp. 1 transcriptome contains a quite complete and reliable database of transcripts. To further compare our assembly, we also performed a de novo transcriptome assembly adding an RNA-Seq dataset from the USDA-ARS (performed on the same A. fraterculus morphotype and with similar experimental design). Despite similar results in terms of BUSCO ortholog detection was obtained in the combined assembly, far fewer assembled and annotated transcripts were recovered. We suspect that datasets in which different populations are combined, can potentially generate quimeras and truncated transcripts that overwhelm the assembly process. Therefore, combining datasets from different populations and sequenced by different groups does not necessarily improve the yielded transcriptome assembly.
When comparisons were made considering all predicted proteins from the genomes of three closely related species (B. oleae, $R$. zephyria, and C. capitata), A. fraterculus sp. 1 transcriptome showed a good sequence representation (indicated by BUSCO and OrthoMCL results). Furthermore, BUSCO analysis showed $33.4 \%$ of complete and duplicated transcripts, showing that the information is somewhat redundant, probably evidencing the presence of potential ambiguously identified isoforms or due to the presence of fragmented sequences. However, a very strict filtering process using EdgeR and a deep manual processing allowed us to unambiguously identify a set of transcripts associated with early development, sex determination, and physiological pathways related to courtship and communications, which were further evaluated by qPCR. In fact, we detected a high positive correlation between RNA-Seq and qPCR data which suggests our methodology was robust enough.

The expression analysis of selected transcripts by qPCR in $72 \mathrm{~h}$ embryos, as well as virgin and mated males and females of $A$. fraterculus sp. 1 showed differential patterns mainly associated with their developmental stage and physiological status. The transformer-2 gene has been previously reported as an essential switch for the sex determination cascade in several dipteran insect species [30, 51-53]. Recently, Zheng et al. [54] found that this gene was up-regulated in sexually mature 
females of $B$. dorsalis compared to their newly emerged counterparts and showed a higher expression in ovaries than in other tissues. In the present study, we found overall low expression level of this gene in both $72 \mathrm{~h} \mathrm{em-}$ bryos and virgin and mated adults of $A$. fraterculus. Interestingly, the expression level of transformer-2 was higher in mated than in virgin females. This result is in line with Zheng et al. [54], who suggested that sex determination related genes, such as transformer-2, may also function during sex maturation. We identified in our transcriptome two other transcripts with high similarity to genes involved in sex-determination and developmental pathways (serendipity alpha and heat shock protein 27). While serendipity alpha showed early expression in C. capitata [55] and B. oleae [56], our expression analysis revealed similar and low levels of this transcript in both $72 \mathrm{~h}$ embryos and adults of $A$. fraterculus. The analysis of $72 \mathrm{~h}$ embryos may not be the proper developmental time to detect the expected high expression of serendipity alpha for this species, which it probably reduces during late embryogenesis, as was previously described for other tephritid species [52, 53, 55]. The heat shock protein 27 transcript did show an overexpression in embryos relative to males, and in females relative to males, for both virgin and mated individuals. These results are in line with those obtained in C. capitata $[57,58]$, which showed high level of heat shock protein 27 RNA in mature ovaries and newly laid eggs, possibly indicating that this early embryonic RNA comes from the mature eggs and remains at a high expression during late embryogenesis. In addition to the analysis of these transcripts, the screening of the $A$. fraterculus transcriptome allowed to identify the presence of other early genes involved in development and sex-determination pathways (transformer, sex-lethal, daughterless, doublesex and slow-as-molasses), all of which showed a low expression level at the stages evaluated in this study.

Two of the candidate genes (takeout-like and odorantbinding protein 50a1) involved in courtship [59-61] and mate choice [45, 62-65] in insects, respectively, showed very low expression in embryos and differences in their expression level between males and females of $A$. fraterculus. Specifically, the transcript annotated as takeoutlike was over-expressed in males relative to females independently of their reproductive status (virgin vs mated individuals). While sexual maturation and mating in insects are generally accompanied by major physiological and behavioural changes [66, 67], in the present study we found no changes in takeout-like expression between virgin and mated flies, despite the physiological changes occurring after copulation. In fact, in a transcriptomic analysis performed on $C$. capitata, the takeout gene showed enriched transcript abundance in mature relative to virgin females [66]. In relation to the odorant-binding protein 50a1 transcript, we found that, in both virgins and mated adults, this transcript was over-expressed in females compared to males. Our results showed non- statistically significant differences between virgin vs mated females, consistently with previous results obtained by Campanini et al. [45] for an unidentified $A$. fraterculus morphotype from Brazil. However, we did detect higher expression of this transcript in mated than in virgin males. Conversely, Campanini et al. [45] showed non-significant difference for this comparison. Interestingly, these authors suggested that the up-regulation in post-mating males observed for other several odorant-binding proteins in A. fraterculus would be related to the involvement of mature males in lek formation, also supported by previous study performed in C. capitata [66] even after initial mating. Present results support the hypothesis that odorantbinding protein $50 a 1$ may be associated with courtship and mating in A. fraterculus sp.1, as proposed for other odorant-binding proteins for which expression level changed after mating. It is worth noting that our results were obtained by analyzing the gene expression in a narrow post-copulation temporal window of whole-body adults. Further studies in this $A$. fraterculus morphotype should include the analysis of different tissues and maturation statuses as well as a wider pre- and post-mating temporal window. Studying these conditions will shed light on the effect of the expression of odorant-binding protein 50a1 and takeout-like genes, along with other selected genes (e.g. transcripts associated with response to stimulus, odorant receptors, co-receptors, chemosensory proteins) on the physiological modifications associated with the mating behaviour in males and females of $A$. fraterculus. In addition, the expression profile and physiological role of other related odorant-binding proteins and their potential isoforms must be further evaluated.

Finally, we analyzed the expression profiles of two genes associated with metabolic processes (maltase 2like and androgen-induced gene 1). The transcript annotated as maltase 2-like evidenced high homology with the predicted maltase-2-like of $Z$. cucurbitae and also showed considerable similitude with the gene maltase $B 2$ of D. melanogaster involved in the metabolism of Dglucose [68]. The analysis of this transcript showed differential expression between embryos and male and female adults. In particular, $72 \mathrm{~h}$ embryos and females exhibited higher level of this transcript in comparison to males, probably indicating the differential energetic demands of the embryos and females. Interestingly, a member of the same family, maltase-D (A2 in D. melanogaster) is the most up-regulated gene in males after mating in $B$. dorsalis [69]. Although no differences were observed between virgin and mated individuals of both 
sexes, further research is needed to determine whether maltase 2-like could also have a role in mating in $A$. fraterculus. With respect to the androgen-induced gene 1, our results showed an over-expression of this transcript in males relative to embryos, but no significant differences between the sexes or physiological status (virgin vs mated individuals). This gene was found to be associated with the regulation of processes in the male's accessory glands, enhanced by mating, and in combination with the bone morphogenetic protein (BMP) and the ecdysone receptor (EcR) [70]. Regarding tephritid flies, B. dorsalis is the species for which this gene was studied, and six isoforms have been identified [71, 72], but no functional characterization has been performed to date. Although we detected and analyzed only one isoform for this specific gene (androgen-induced gene $1 \mathrm{X} 1$ isoform), isoforms of genes of interest should be considered, in general, for further physiological and functional studies in order to distinguish their action separately.

A final contribution of our transcriptome analysis is the discovery of thousands of microsatellite markers. Here we described the presence of more than 11,000 transcripts containing microsatellite motifs, with the potential to be used in the characterization of the genetic variability of natural and laboratory populations of $A$. fraterculus from Argentina, and these markers can be added to those previously developed for this species [73-75]. These markers could also be useful in developing diagnostic molecular tools to analyze the genetic quality of laboratory populations and mass rearing production of this pest species (e.g. inbreeding or deleterious genotype analyses) and the incidence of evolutionary forces, such as selection and genetic drift acting in conjunction with ecological processes [76-78]. Furthermore, these transcriptome-derived microsatellite markers (commonly situated close to or within genes) increase their cross-species transferability, potentially being of help to elucidate the cryptic species within the $A$. fraterculus complex if more genomic information is generated from $A$. fraterculus morphotypes and close related species.

\section{Conclusion}

Here we present a fairly complete $A$. fraterculus sp. 1 transcriptome of $72 \mathrm{~h}$ embryos and adults. The identification of transcripts and the expression analysis of candidate genes potentially involved in early development, reproduction and courtship provide a resource for future isolation and functional characterization of genes underlying relevant metabolic pathways, expanding our knowledge on physiological aspects of this pest species and also supporting the development of genetic control strategies. In addition, the set of identified microsatellites provides potentially polymorphic markers useful to monitor the pest in the field and supports the characterization of laboratory strains for SIT purpose.

\section{Methods \\ Fly culture and stocks}

A. fraterculus IGEAF laboratory strain kept at the National Institute of Agricultural Technology (INTA) (Hurlingham, Buenos Aires, Argentina) was used in this study. It was established in 2007 with approximately 10, 000 A. fraterculus sp. 1 pupae and maintained under standard rearing conditions for 120 generations, following the procedures described by Vera et al. [79] and Jaldo et al. [80] without refreshing (i.e. no wild material was introduced to refresh the genetic background). This laboratory strain was derived from a semi-mass rearing colony kept at Estación Experimental Agroindustrial Obispo Colombres, Tucumán, Argentina, initiated in 1997 with wild pupae recovered from infested guavas (Psidium guajava L.) collected in the vicinity of Tafí Viejo, Tucumán, Argentina [81]. The strains were identified as A. fraterculus by Dr. R. Zucchi and Dr. V. Hernandez-Ortiz.

\section{Adult and egg collection}

A. fraterculus sp. 1 eggs were collected from 15-day-old mated females following standard procedures [79]. Briefly, adults were exposed to oviposition units for 30 min and then the eggs were collected, washed with tap water, and immersed in water in an incubator with agitation for $72 \mathrm{~h}$. Next, $72 \mathrm{~h}$ embryos were immediately processed for RNA isolation and transcriptome analysis. This procedure was repeated increasing the number of eggs collected in order to obtain the adequate quantity of eggs to obtain four replicates for qPCR assays.

For adult collection, $30 \mathrm{~A}$. fraterculus sp. 1pupae were recovered from the laboratory experimental rearing. Upon emergence, males and females were separated and kept in $1 \mathrm{~L}$ glass flask with water and food [79, 80]. Five 15-day-old adults (sexually mature unmated males and females) were randomly sampled and processed for RNA isolation and transcriptome analysis. This procedure was repeated increasing the number of pupae recovered in order to obtain the adequate quantity of adults to obtain four replicates of each sex for qPCR assays.

\section{RNA isolation and libraries preparation for RNA-Seq analysis}

Total RNA was isolated from two pools of five adult individuals (one pool of each sex; whole-body adult insects) and a pool of $25 \mathrm{mg}$ of $72 \mathrm{~h}$ embryos. The TRIzol ${ }^{\circ}$ Reagent (Thermo Fisher Scientific) was used for RNA isolation following the manufacturer's instructions. The integrity of RNA was assessed by $1 \% \mathrm{w} / \mathrm{v}$ agarose gel electrophoresis, and the quantity and quality of all RNA samples were evaluated using a spectrophotometer 
(NanoDrop1000, Thermo Fisher Scientific) and a fluorometer (Qubit 4, Thermo Fisher Scientific) at the Genomic Unit UGB (Instituto de Biotecnología, IABIMO, INTA - CONICET).

Approximately $50 \mathrm{ng}$ of total RNA from whole-body adults (virgin females, virgin males) and eggs $(72 \mathrm{~h}$ embryos) of $A$. fraterculus were used for library construction (Illumina TruSeq Stranded mRNA kit) and subsequent sequencing via Illumina MiSeq platform. Paired-end reads of $2 \times 150$ bases were generated for further analysis and processed at the Genomic Unit (UGB, Instituto de Biotecnología, IABIMO, INTA - CONICET).

\section{Bioinformatic analysis}

After raw reads were obtained, quality visualized with FastQC [82]. Trimmomatic [83] was used to trim the low-quality ends of all reads and adapter sequences and to discard low-quality reads. Briefly, the trimming process included the following steps: i) Remove adapters (TruSeq2-PE), leading low quality or $\mathrm{N}$ bases (below quality 3; LEADING: 3) and trailing low quality or $\mathrm{N}$ bases (below quality 3; TRAILING: 3); ii) Scan the read with a 4-base wide sliding window, cutting when the average quality per base drops below 15; iii) Drop reads below the 50 bases long; and iv) Remove the first 11 bases from reads. The remaining reads were merged into one longer read if both paired reads could align with each other using the Flash software [84]. All paired and unpaired reads of the libraries were assembled to construct the reference transcriptome using the Trinity v2.1.1 assembler [85] with a k-mer of 25, a max_memory 100G, and $10 \mathrm{CPU}$ max usage.

The $A$. fraterculus assembly was evaluated using the BUSCO (benchmarking universal single-copy orthologs) software with the Diptera database (version 2019-11-20), which uses 2799 near-universal single-copy orthologs to assess the relative completeness of genome and transcriptome assemblies [86].

Annotation of the assembled sequences was obtained by aligning to the NCBI non-redundant (nr) protein database using BLASTX [87] and collecting the GO annotations with the BLAST2GO tool [88].

\section{Ortholog prediction and quality analysis of $A$. fraterculus transcriptome data Selection of closely related species}

A selection of related Tephritidae species was done considering previous phylogenetic studies of the family $[48,49]$ and organisms which fit the following criteria: i) Available and fully annotated genome (RefSeq Genomes DB NCBI) (https://www.ncbi.nlm.nih.gov/datasets/geno mes/?txid=7211\&source_db=RefSeq); ii) One species from each genus; and iii) Available 18S rRNA nucleotide sequence (BLASTN search; RefSeq Genomes DB; Query: 18S rRNA gene complete sequence [AF187101.2]); considering $\mathrm{E}$ value, \% of identity and query coverage parameters) (Additional File 3).

All predicted proteins were identified using the TransDecoder software with default parameters and each predicted protein was at least 100 amino acids long. The general ortholog prediction was performed with OrthoMCL software using the complete proteomes of selected closely related Tephritidae species.

\section{Analysis of differentially expressed transcripts}

Low-quality bases (average Q-score below 20) and adapter sequences were trimmed, and sequences less than 36 bases long were removed with Trimmomatic [83]. The remaining reads were mapped to the assembled transcriptome with Bowtie2, using the global-sensitive parameter and allowing all multi-mapping reads to be mapped [89]. The expectation-maximization (EM) algorithm of eXpress was used for more reliable transcriptome quantification [90]. Differential gene expression analysis was performed with the program EdgeR [50]. Briefly, transcripts with less than 10 counts per million (cpm) in one or more samples were filtered out. We performed normalization of the data using the trimmed mean of M-values (TMM) method. Read counts for each gene were fit to a negative binomial model and gene-wise exact tests were computed for differences in the means between two groups using the exactTest function of EdgeR. As was previously mentioned, we set the common Biological coefficient of variation (bcv) value to 0.4 as proposed for an experimental design without biological replicates. Typical values for the common bcv (square- root-dispersion) range from 0.4 in human experiments to 0.1 for data on genetically identical model organisms [50]. Transcripts were considered differentially expressed between groups if they had a $P$ value corrected by False Discovery Rate (FDR) lower than 0.05 .

\section{Selection of candidate genes for qPCR analysis}

We performed a filtering process based on the following criteria: transcripts with more than 10 counts per million $(\mathrm{cpm}>10)$ in paired-comparisons between libraries; a threshold criterion of FC (fold change, defined as a ratio of $\mathrm{cpm}$ between compared libraries) with $\mathrm{FC}>10$ for over-representation and $\mathrm{FC}<0.1$ for under-representation; the annotation (or predicted function) considering the GO groups assigned, and/or the best BLAST hit searches.

The selection of transcripts was based on differences in the number of counts per million (cpm) obtained in paired-comparisons between libraries and their predicted function (Additional File 6 B). In addition, our transcriptome was screened for genes previously reported in the literature associated with reproduction and early 
expression (not present in the database mentioned above) based on previous studies performed in related species (Additional File $7 \mathrm{~A}$ and B).

\section{Differential expression analysis of selected transcripts by qPCR}

For the expression analysis of selected candidate genes (heat shock protein 27, odorant-binding protein 50a1, transformer-2, takeout-like, maltase 2-like, androgen-induced gene 1 protein and serendipity alpha), total RNA was extracted from four pools of five sexually mature 15-day-old unmated males, five sexually mature 15-day-old unmated females (four biological replicates of each sex) and four pools of $72 \mathrm{~h}$ embryos ( $25 \mathrm{mg}$ each). To obtain these biological replicates of $72 \mathrm{~h}$ embryos and adults, we followed the same procedures described above (adult and egg collection). In addition, the expression analysis of a subset of the selected candidate genes (heat shock protein 27, odorant-binding protein 50a1, transformer-2, takeout-like, maltase 2-like, androgeninduced gene 1 protein) was compared between virgin and mated sexually mature females and males. Briefly, sexually mature 15-day-old individuals of both sexes were mixed in the same glass flask and allowed to mate. Each couple were separated from the flask and observed. The couples for which copulation lasted more than $30 \mathrm{~min}$ were considered "mated". After $2 \mathrm{~h}$, the insects were processed for RNA isolation. Four pools of five mated females and five mated males were prepared (four biological pool replicates of each sex). RNA was extracted using TRIzol ${ }^{\circ}$ Reagent (Thermo Fisher Scientific).

The resultant RNA was resuspended in $20 \mu \mathrm{l}$ of DEPC-treated water. The quantity and quality of RNA were assessed using a Nanodrop spectrophotometer (Thermo Scientific Nanodrop 1000) and agarose gel electrophoresis $(1 \% \mathrm{w} / \mathrm{v})$. About $1 \mu \mathrm{g}$ of total RNA was used as a template to synthesize first-strand cDNA using ImProm-II Reverse Transcriptase (Promega) and Oligo (dT) primers (Promega), following the manufacturer's protocol. The resultant cDNA was diluted $1 / 10$ for further use in real-time quantitative PCR (qPCR) experiments.

Specific primers for the amplification of candidate genes were designed by Primer-BLAST (http://www. ncbi.nlm.nih.gov/tools/primer-BLAST) from the selected transcripts (Table 3; Additional File $7 \mathrm{~A}$ and B).

The qPCR assays were performed in a Light Cycler 96 (Roche), using the cDNA as a template. Each reaction was performed in a total volume of $10 \mu \mathrm{l}$, containing $5 \mu \mathrm{l}$ of Fast Start Essential DNA Green Master (Roche), $0.25 \mu \mathrm{l}(50 \mathrm{mM})$ of each forward and reverse primers, $4 \mu \mathrm{l}$ of ultrapure $\mathrm{H}_{2} \mathrm{O}$ (Roche), and $0.5 \mu \mathrm{l}$ of cDNA template (1:10 dilution). The cycling parameters were $95^{\circ} \mathrm{C}$ for $5 \mathrm{~min}$ followed by 40 cycles of $95^{\circ} \mathrm{C}$ for $10 \mathrm{~s}$ and $60^{\circ} \mathrm{C}$ for $45 \mathrm{~s}$, ending with a melting curve product amplification. All qPCRs were performed in triplicate (i.e. three technical replicates). A total of four biological replicates for each of the five groups $(72 \mathrm{~h}$ embryos, unmated females, unmated males, mated females, mated males) were performed. Expression values were calculated relative to the reference $r p L 18$ and $e f-1 a$ genes (Table 3) based on the recommendations made by Campanini et al. [45]. The stability and suitability of these reference genes were evaluated with the BestKeeper algorithm [91].

To analyze the expression profiles of the candidate genes, we applied the NRQ model, which consists in converting quantification cycle values $(\mathrm{Cq})$ into NRQ (normalized relative quantities) values, adjusting for differences in PCR efficiency between the amplicons [92] and normalizing the data using multiple reference genes [93]. We calculated the relative quantities and normalized the data following the formulas in [93]. Differences in $\log$ (NRQ) between groups were evaluated using the t-test.

\section{Validation of transcriptome expression data with qPCR}

Gene expression levels obtained by RNA-Seq and qPCR techniques for the nine transcripts (Table 3) were compared using their Fold Change (FC) values and analyzed with the Spearman Rank Correlation index to observe consistency. Correlations were performed for each of the three comparisons $(72 \mathrm{~h}$ embryos vs virgin females, $72 \mathrm{~h}$ embryos vs virgin males, virgin males vs virgin females) using the transcript log2 FC for RNA-Seq and the mean NRQ $\log 2$ FC for qPCR data. Correlation coefficient $r$ and $P$ values were obtained for each comparison. Data used to generate $\mathrm{FC}$ values are listed in Additional File 7 $A$ and $B$ (RNA-Seq) and Fig. 3 (qPCR).

\section{SSR discovery}

To identify SSRs markers, we ran the software MISA [http://pgrc.ipk-gatersleben.de/misa/misa.html]. The criteria used for SSR selection were based on the minimum number of repeats as follows: five for dinucleotide, four for trinucleotide, three for tetra, penta, and hexanucleotide motifs.

To design pairs of primers with no genome information available that amplify the corresponding SSR marker in every transcript, we ran an in-house script that uses EPRIMER32 from the EMBOSS package (http://emboss.open-bio.org/wiki/Appdocs). An in silico PCR was performed on all SSR using the assembled transcriptome (in-house script). 


\section{Supplementary Information}

The online version contains supplementary material available at https://doi. org/10.1186/s12863-020-00943-2

Additional file 1. A. fraterculus sp. 1 transcripts $\mathrm{GO}$ assignment. The results of level $3 \mathrm{GO}$ annotation are summarized in the three main categories "cellular component", "molecular function" and "biological process". A total of 28,756 transcripts were assigned. The percentage (left Y-axis) and total number (right Y-axis) of transcripts in each category are shown. Y-axes are in log (10) scale. WEGO was used to produce the graph.

Additional file 2. Gene Ontology (GO) analysis of A. fraterculus sp. 1 transcripts. The table shows main terms at the second and third GO levels involved in biological processes, development, behaviour, and reproduction.

Additional file 3. Sequence information of related Tephritidae species available in the NCBI RefSeq_Genomes database.

Additional file 4. Prediction of orthologs from closely related species ( $B$. oleae and R. zephyria) and the best-annotated tephritid species (C. capitata).

Additional file 5. EdgeR results. Each Excel sheet shows the pairedcomparison between libraries ( $72 \mathrm{~h}$ embryo vs male; female vs male; and female vs $72 \mathrm{~h}$ embryo). LogFC: logarithm of the fold change for each contrast performed; LogCPM: logarithm of the counts per million for each transcript; $P$ value: statistical $P$ value for the individual test performed; FDR: false discovery rate (adjusted $P$ value considering multiple testing).

Additional file 6. A. List of differentially expressed transcripts obtained in paired-comparisons of libraries. A.1. $72 \mathrm{~h}$ embryos vs female (A.1.1. transcripts over-expressed in embryos; A.1.2. transcripts over-expressed in females); A.2. $72 \mathrm{~h}$ embryos vs male (A.2.1. transcripts over-expressed in embryos; A.2.2. transcripts over-expressed in males); and A.3. female vs male (A.3.1. transcripts over-expressed in females; A.3.2. transcripts over-expressed in males). B. Functional annotation of differentially expressed transcripts between libraries. Only transcripts with CPM $>10$ and $70-100 \%$ complete sequence (related to the best BLAST hit) are shown. Over-expressed transcripts: sequences with FC $>10$; Underexpressed transcripts: sequences with $\mathrm{FC}<0.1$.

Additional file 7. Selection of putative transcripts associated with function of interest. A. Transcripts selected according to their differential expression among libraries and predicted function (GO or BLAST hit). B. Transcript selected according to the literature associated to early development, sex determination, and communication.

Additional file 8. Correlation between RNA-Seq and $q P C R$ datasets for the nine analyzed transcripts (Table 3 ) in $72 \mathrm{~h}$ embryos, virgin males and virgin females of $A$. fraterculus. For each comparison, transcripts log 2 FC from RNA-Seq analysis are plotted against the mean NRQs log2 fold change from qPCR analysis. Spearman's rank correlation coefficients ( $r$ ) for each comparison are shown. For the three comparisons, $r$ values were highly significant $(P<0.0001)$ and demonstrate a high degree of correlation between the two datasets. Data used to create these graphs are detailed in Additional File 7 (RNA-Seq data) and Fig. 4 (qPCR data).

Additional file 9. List of transcripts containing microsatellite motifs and description by repeat type classes and number of repeating motif.

Additional file 10. List of transcripts containing microsatellite motif and primers designed available to be tested.

\section{Abbreviations}

RNA-seq: Whole transcriptome sequencing; SIT: Sterile Insect Technique; GSS: Genetic sexing strain; CRISPR: Clustered regularly interspaced short palindromic repeats; GO: Gene ontology; qPCR: quantitative PCR; bp: base pairs; BLAST: Basic Local Alignment Search Tool; NR: Non-redundant; NCBI: National Center for Biotechnology Information; BUSCO: Benchmarking universal single-copy orthologs; ORFs: Open reading frames; DE: Differential expressed; Cpm: Counts per million; FC: Fold-change; SSR: Simple sequence repeat; BMP: Bone morphogenetic protein; EcR: Ecdysone receptor; rRNA: ribosomal RNA; TMM: Trimmed mean of M-values; bcv: Biological coefficient of variation; FDR: False Discovery Rate; NRQ: Normalized relative quantities

\section{Acknowledgments}

This study was supported by the International Atomic Energy Agency research contact no. 18822 as part of the Coordinated Research Project "Comparing Rearing Efficiency and Competitiveness of Sterile Male Strains Produced by Genetic, Transgenic or Symbiont-based Technologies". The authors are grateful to Andrea Puebla and Pablo Vera (UGB, Instituto de Biotecnología, INTA, IABIMO-CONICET) for their support in sample processing and sequencing. We thank the Editor and the three anonymous Reviewers for their careful reading of our manuscript and their many insightful comments and suggestions.

\section{About this supplement}

This article has been published as part of BMC Genetics Volume 21 Supplement 2, 2020: Comparing rearing efficiency and competitiveness of sterile male strains produced by genetic, transgenic or symbiont-based technologies. The full contents of the supplement are available online at https://bmcgenet.biomedcentral.com/articles/supplements/volume-21-supplement-2.

\section{Authors' contributions}

ACS, CAC, JLC and SBL designed the study. CAC, ACS, FM, JPW, and IM performed the laboratory work. ACS and SBL wrote the manuscript. MR, AR, JPW and CAC participated in bioinformatic analysis and helped to draft the manuscript. All the authors read and approved the final manuscript.

\section{Funding}

This work was financially supported by the International Atomic Energy Agency research contact no. 18822 as part of the Coordinated Research Project "Comparing Rearing Efficiency and Competitiveness of Sterile Male Strains Produced by Genetic, Transgenic or Symbiont-based Technologies" and the National Institute of Agricultural Technology (INTA) through the project PNBIO 1131044 to SBL; and by the National Scientific and Technological Promotion Agency (ANPCyT) through the project PICT N²012 0704 to JLC. The funding Institutions supported the costs of insect rearing, transcriptome sequencing service, data analysis and English editing of the manuscript. Publication costs are funded by the Joint FAO / IAEA Division of Nuclear Techniques in Food and Agriculture, IAEA (CRP No.: D4.20.16) Vienna, Austria.

\section{Availability of data and materials}

Raw sequence reads of $A$. fraterculus transcriptome have been submitted to NCBI Sequence Read Archive (SRA) under the accession number of BioProject ID: PRJNA606292 (SRR11095951-53)

Ethics approval and consent to participate Not applicable.

\section{Consent for publication}

Not applicable.

\section{Competing interests}

The authors declare no competing financial interests.

\section{Author details}

'Instituto de Genética "E. A. Favret" (IGEAF) gv Instituto de Agrobiotecnología y Biología Molecular (IABIMO), Instituo Nacional de Tecnología Agropecuaria (INTA) - Consejo de Investigaciones Científicas y Técnicas (CONICET), Hurlingham, Buenos Aires, Argentina. ${ }^{2}$ Instituto de Biotecnología, IABIMO, INTA - CONICET, Hurlingham, Buenos Aires, Argentina.

Published: 18 December 2020

\section{References}

1. Norrbom AL, Zucchi RA, Hernández-Ortiz V. Phylogeny of the genera Anastrepha and Toxotrypana (Trypetinae: Toxotrypanini) based on morphology. In: Aluja M, Norrbom AL, editors. Fruit flies (Tephritidae): phylogeny and evolution of behavior. Boca Raton: CRC Press; 1999.

2. Ovruski S, Schliserman P, Aluja M. Native and introduced host plants of Anastrepha fraterculus and Ceratitis capitata (Diptera: Tephritidae) in northwestern Argentina. J Econ Entomol. 2003;96:1108-18.

3. Norrbom AL. Host plant database for Anastrepha and Toxotrypana (Diptera: Tephritidae: Toxotrypani), Diptera Data Dissemination Disk. CD 2004, - not a journal. 
4. Zucchi RA. Diversidad, distribución y hospederos del género Anastrepha en Brasil. In: Hérnandez-Ortiz V, editor. Moscas de la fruta en Latinoamérica (Diptera: Tephritidae): Diversidad, biología y manejo. S y G editores, Distrito Federal; 2007. p. 77-100.

5. Cladera JL, Vilardi JC, Juri M, Paulin LE, Giardini MC, Gómez Cendra PV, et al. Genetics and biology of Anastrepha fraterculus: research supporting the use of the sterile insect technique (SIT) to control this pest in Argentina. BMC Genet. 2014;15(Suppl 2):S12.

6. Steck GJ. Taxonomic status of Anastrepha fraterculus. The South American fruit fly, Anastrepha fraterculus (Wied.): advances in artificial rearing, taxonomic status and biological studies. Vienna: International Atomic Energy Agency; 1999. p. 13-20. [IAEA-TECDOC-1064.

7. Enkerlin WR. Impact of fruit fly control programmes using the sterile insect technique. In: Dyck VA, Hendrichs J, Robinson AS, editors. Sterile insect technique - principles and practice in area-wide integrated Pest management. Dordrecht: Springer; 2005.

8. Hendrichs J, Vera MT, De Meyer M, Clarke AR. Resolving cryptic species complexes of major tephritid pests. In: De Meyer M, Clarke AR, Vera MT, Hendrichs J, editors. Resolution of cryptic species complexes of Tephritid pests to enhance SIT application and facilitate international trade. ZooKeys, vol. 540; 2015. p. 5-39.

9. Stone A. The fruit flies of the genus Anastrepha, vol. 439. Washington DC: United States Department of Agriculture Miscellaneous Publication; 1942. p. 1-112.

10. Goday C, Selivon D, Perondini ALP, Graciano PG, Ruiz MF. Cytological characterization of sex chromosomes and ribosomal DNA location in Anastrepha species (Diptera: Tephritidae). Cytogenet Genome Res. 2006;114:70-6.

11. Hernández-Ortiz V, Bartolucci AF, Morales-Valles P, Frías D, Selivon D. Cryptic species of the Anastrepha fraterculus Complex (Diptera: Tephritidae): a multivariate approach for the recognition of south American Morphotypes. Ann Entomol Soc Am. 2012;105:305-18.

12. Hernández-Ortiz V, Canal NA, Tigrero Salas JO, Ruíz-Hurtado FM, Dzul-Cauich JF. Taxonomy and phenotypic relationships of the Anastrepha fraterculus complex in the Mesoamerican and Pacific Neotropical dominions (Diptera, Tephritidae). Zookeys. 2015;540:95-124.

13. Knipling EF. Possibilities of insect control or eradication through the use of sexually sterile males. Econ Entomol. 1955;48:459-62.

14. Dyck VA, Hendrichs J, Robinson AS. Sterile Insect Technique: Principles and Practice in Area-Wide Integrated Pest Management. the Netherlands: Springer; 2005.

15. Hendrichs J, Robinson AS, Cayol JP, Enkerlin W. Medfly areawide sterile insect technique programmes for prevention, supression or erradication: the importance of mating behavior studies. Fla Entomol. 2002;85:1-13.

16. Orankanok W, Chinvinijkul S, Thanaphum S, Sittilob P, Enkerlin WR. Areawide integrated control of oriental fruit fly Bactrocera dorsalis and guava fruit fly Bactrocera correcta in Thailand. In: Vreysen MJB, Hendrichs J, Robinson AS, editors. Area-wide control of insect pests: from research to field implementation. Dordrecht: Springer; 2007. p. 517-26.

17. Hernández E, Orozco D, Flores Breceda S, Domínguez J. Dispersal and longevity of wild and mass-reared Anastrepha ludens and Anastrepha obliqua (Diptera: Tephritidae). Fla Entomol. 2007:90:123-35.

18. Meza JS, Fleischer FD, Orozco D. Pupariation time as a source of variability in mating performance in mass-reared Anastrepha ludens (Diptera: Tephritidae). J Econ Entomol. 2005;98:1930-6.

19. Zepeda-Cisneros CS, Hernández JSM, García-Martínez V, Ibañez-Palacios J, Zacharopoulou A, Franz G. Development, genetic and cytogenetic analyses of genetic sexing strains of the Mexican fruit fly, Anastrepha ludens Loew (Diptera: Tephritidae). BMC Genet. 2014;15:Suppl 2-S1.

20. Guillén D, Sánchez R. Expansion of the National Fruit fly Control Programme in Argentina. In: Vreysen MJB, Robinson AS, Hendrichs J, editors. Area-wide control of insect pests. Dordrecht: Springer; 2007.

21. Rendón P, Mclnnis D, Lance D, Stewart J. Medfly (Diptera: Tephritidae) genetic sexing: large-scale field comparison of males-only and bisexual sterile fly releases in Guatemala. J Econ Entomol. 2004;97:1547-53.

22. Lutrat C, Giesbrecht D, Marois E, Whyard S, Baldet T, Bouyer Y. Sex sorting for Pest control: It's raining men! Trends Parasitol. 2019;35:649-62.

23. Meza JS, Cáceres C, Bourtzis K. Slow larvae mutant and its potential to improve the Pupal color-based genetic sexing system in Mexican fruit Fly, (Diptera: Tephritidae). J Econ Entomol. 2019;112:1604-10.

24. McCombs SD, Reyes-Flores J, Ramos MDLS, Gersabeck E. Animal and Plant Health Inspection Service United States and Mexico lower Rio Grande Valley Mexican fruit Fly eradication program review. Report. USDA-APHIS: Raleigh, NC; 2009.
25. Hendrichs J, Franz G, Rendon P. Increased effectiveness and applicability of the sterile insect technique through male-only releases for control of Mediterranean fruit flies during fruiting seasons. J Appl Entomol. 1995:119:371-7.

26. Franz G. Genetic sexing strains in mediterranean fruit fly, an example for other species amenable to large-scale rearing for the sterile insect technique. In: Dyck, V.A., Hendrichs, J., and Robinson, A. S, Eds. Sterile Insect Technique. Dordrecht: Springer, 2005.

27. Mclnnis DO, Tam S, Lim R, Komatsu J, Kurashima R, Albrecht C. Development of a pupal color-based genetic sexing strain of the melon fly, Bactrocera cucurbitae (Coquillett) (Diptera: Tephritidae). Ann Entomol Soc Am. 2004;97:1026-33.

28. IAEA, Vienna, Austria. Webpage https:/nucleus.iaea.org/sites/naipc/dirsit/Pages/ Insect\%20colonies\%20available\%20at\%20IPCL.aspx. Accessed 20 Mar 2020.

29. Ruiz MF, Milano A, Salvemini M, Eirín-López JM, Perondini ALP, Selivon D, Polito C, Saccone G, Sánchez L. The gene transformer of Anastrepha fruit flies (Diptera, Tephritidae) and its evolution in insects. PLoS One. 2007;2:11.

30. Sarno F, Ruiz MF, Eirín-López JM, Perondini AL, Selivon D, Sánchez L. The gene transformer-2 of Anastrepha fruit flies (Diptera, Tephritidae) and its evolution in insects. BMC Evol Biol. 2010;10:140.

31. Ruiz MF, Stefani RN, Mascarenhas RO, Perondini ALP, Selivon D, Sánchez L The gene doublesex of the fruit fly Anastrepha obliqua (Diptera, Tephritidae). Genetics. 2005;171:849-54.

32. Sim SB, Kauwe AN, Ruano REY, Rendon P, Geib SM. The ABCs of CRISPR in Tephritidae: developing methods for inducing heritable mutations in the genera Anastrepha, Bactrocera and Ceratitis. Insect Mol Biol. 2019;28(2):277-89.

33. Tsoumani KT, Meccariello A, Mathiopoulos KD, Papathanos PA. Developing CRISPR-based sex-ratio distorters for the genetic control of fruit fly pests: a how to manual. Arch Insect Biochem Physiol. 2020;103:e21652.

34. Thornhill R, Alcock J. The evolution of insect mating systems. Cambridge: Harvard University Press; 1983.

35. Fowler K, Partridge L. A cost of mating in female fruit flies. Nature. 1989;338: 760-1.

36. Miyatake T, Yamagishi M. Rapid evolution of larval development time during mass-rearing in the melon fly, Bactrocera cucurbitae. Res Popul Ecol. 1999:41:291-4.

37. Vera MT, Ruiz MJ, Oviedo A, Abraham S, Mendoza M, Segura DF, et al. Fruit compounds affect male sexual competitiveness in the south American fruit fly, Anastrepha fraterculus (Diptera: Tephritidae). J Appl Entomol. 2013;137:2-10.

38. Brízová R, Mendonça A, Vanícková L, Mendonça AL, Da Silva CE, Tomčala A. Aguiar Jordão Paranhos B, et al. pheromone analyses of the Anastrepha fraterculus (Diptera: Tephritidae) cryptic species complex. Fla Entomol. 2013;96:1107-15.

39. Bachmann GE, Segura DF, Devescovi F, Juárez ML, Ruiz MJ, Vera MT, et al. Male sexual behavior and pheromone emission is enhanced by exposure to guava fruit volatiles in Anastrepha fraterculus. PLoS One. 2015;10:1-17.

40. Segura DF, Petit-Marty N, Sciurano R, Vera MT, Calcagno G, Allinghi A, et al. Lekking behavior of Anastrepha fraterculus (Diptera: Tephritidae). Fla Entomol. 2007;90:154-62

41. Segura DF, Belliard SA, Vera MT, Bachmann GE, Ruiz MJ, Jofré Barud F, et al. 2018. Plant chemicals and the sexual behavior of male Tephritid fruit flies. Ann Entomol Soc Am. 2018;111:239-64.

42. Rezende VB, Congrains C, Lima AL, Campanini EB, Nakamura AM, et al. Head transcriptomes of two closely related species of fruit flies of the Anastrepha fraterculus group reveals divergent genes in species with extensive gene flow. G3 (Bethesda, Md.). 2016:6:3283-95.

43. Nakamura AM, Chahad-Ehlers S, Lima AL, Taniguti CH, Sobrinho I Jr, Torres FR, de Brito RA. Reference genes for accessing differential expression among developmental stages and analysis of differential expression of OBP genes in Anastrepha obliqua. Sci Rep. 2016;6:17480.

44. Campanini EB, de Brito RA. Molecular evolution of odorant-binding proteins gene family in two closely related Anastrepha fruit flies. BMC Evol Biol. 2016;16:198.

45. Campanini EB, Congrains C, Torres FR de Brito RA. Odorant-binding proteins expression patterns in recently diverged species of Anastrepha fruit flies. Sci Rep. 2017:7:2194.

46. Congrains C, Campanini EB, Torres FR, Rezende VB, Nakamura AM, de Oliveira $A$, et al. Evidence of adaptive evolution and relaxed constraints in sex-biased genes of south American and West Indies fruit flies (Diptera: Tephritidae). Genome Biol Evol. 2018;10:380-95.

47. Dias N, Cagliari D, Kremer F, Neutzling Rickes L, Edson Nava D, Smagghe G, Zotti M. The south American fruit fly: an important pest insect with RNAisensitive larval stages. Front Physiol. 2019;10:794. 
48. Han HY, McPheron BA. Phylogenetic study of selected tephritid flies (Insecta: Diptera: Tephritidae) using partial sequences of the nuclear $18 \mathrm{~S}$ ribosomal DNA. Biochem Syst Ecol. 1994;22:447-57.

49. Mengual X, Kerr P, Norrbom AL, Barr NB, Lewis ML, Stapelfeldt AM, et al. Phylogenetic relationships of the tribe Toxotrypanini (Diptera: Tephritidae) based on molecular characters. Mol Phylogenet Evol. 2017;113:84-112.

50. Robinson MD, McCarthy DJ, Smyth GK. edgeR: a bioconductor package for differential expression analysis of digital gene expression data. Bioinformatics. 2010;26:139-40.

51. Salvemini M, Robertson M, Aronson B, Atkinson P, Polito LC, Saccone G. Ceratitis capitata transformer-2 gene is required to establish and maintain the autoregulation of cc tra, the master gene for female sex determination. Int J Dev Biol. 2009:53:109-20.

52. Schetelig MF, Caceres C, Zacharopoulou A, Franz G, Wimmer EA. Conditional embryonic lethality to improve the sterile insect technique in Ceratitis capitata (Diptera: Tephritidae). BMC Biol. 2009;7:4.

53. Schetelig MF, Handler AM. Strategy for enhanced transgenic strain development for embryonic conditional lethality in Anastrepha suspensa. Proc Natl Acad Sci U S A. 2012;109(24):9348-53.

54. Zheng W, Luo D, Wu F, Wang J, Zhang H. RNA sequencing to characterize transcriptional changes of sexual maturation and mating in the female oriental fruit fly Bactrocera dorsalis. BMC Genomics. 2016;17:194.

55. Gabrieli P, Falaguerra A, Siciliano P, Gomulski LM, Scolari F, et al. Sex and the single embryo: early development in the Mediterranean fruit fly, Ceratitis capitata. BMC Dev Biol. 2010;10:12.

56. Sagri E, Reczko M, Tsoumani KT, Gregoriou ME, Harokopos V, Mavridou AM, et al. The molecular biology of the olive fly comes of age. BMC Genet. 2014a;15(Suppl 2):S8

57. Economou K, Kotsiliti E, Mintzas AC. Stage and cell-specific expression and intracellular localization of the small heat shock protein hsp27 during oogenesis and spermatogenesis in the Mediterranean fruit fly, Ceratitis capitata. J Insect Physiol. 2017;96:64-72.

58. Kokolakis G, Tatari M, Zacharopoulou A, Mintzas AC. The hsp27 gene of the Mediterranean fruit fly, Ceratitis capitata: structural characterization, regulation and developmental expression. Insect Mol Biol. 2008;17:699-710.

59. Gomulski LM, Dimopoulos G, Xi Z, Soares MB, Bonaldo MF, Malacrida AR, Gasperi G. Gene discovery in an invasive tephritid model pest species, the Mediterranean fruit fly, Ceratitis capitata. BMC Genomics. 2008;23(9):243.

60. Dauwalder B, Tsujimoto S, Moss J, Mattox W. The Drosophila takeout gene is regulated by the somatic sex-determination pathway and affects male courtship behavior. Genes Dev. 2002;16:2879-92.

61. Saurabh S, Vanaphan N, Wen W, Dauwalder B. High functional conservation of takeout family members in a courtship model system. PLoS One. 2018;13:e0204615.

62. Siciliano P, Scolari F. Gomulski LM1, Falchetto M, Manni M, et al. sniffing out chemosensory genes from the Mediterranean fruit fly, Ceratitis capitata. PLoS One. 2014:9:e85523.

63. Matsuo T, Sugaya S, Yasukawa J, Aigaki T, Fuyama Y. Odorant-binding proteins OBP57d and OBP57e affect taste perception and host-plant preference in Drosophila sechellia. PLoS Biol. 2007:5:e118.

64. Laughlin JD, Ha TS, Jones DNM, Smith DP. Activation of pheromonesensitive neurons is mediated by conformational activation of pheromonebinding protein. Cell. 2008;133:1255-65.

65. Falchetto M, Ciossani G, Scolari F, Di Cosimo A, Nenci S, Field LM, et al. Structural and biochemical evaluation of Ceratitis capitata odorant-binding protein 22 affinity for odorants involved in intersex communication. Insect Mol Biol. 2019;28:431-43.

66. Gomulski LM, Dimopoulos G, Xi Z, Scolari F, Gabrieli P, et al. Transcriptome profiling of sexual maturation and mating in the Mediterranean fruit fly, Ceratitis capitata. PLOS ONE. 2012;7:e30857.

67. McGraw LA, Clark AG, Wolfner MF. Post-mating gene expression profiles of female Drosophila melanogaster in response to time and to four male accessory gland proteins. Genetics. 2008;179:1395-408.

68. Gabriško M, Janeček Š. Characterization of maltase clusters in the genus Drosophila. J Mol Evol. 2011;72:104

69. Cheng D, Chen L, Yi C, Liang G, Xu Y. Association between changes in reproductive activity and D-glucose metabolism in the tephritid fruit fly, Bactrocera dorsalis (Hendel). Sci Rep. 2014;4:7489.

70. Leiblich A, Hellberg JEEU, Sekar A, Gandy C, Mendes CC, Redhai S, et al. Mating induces switch from hormone-dependent to hormone-independent steroid receptor-mediated growth in Drosophila secondary cells. PLoS Biol. 2019;17: e3000145.
71. Shen GM, Dou W, Niu JZ, Yang WJ, Jia FX, Hu F, Cong L, Wang JJ. Transcriptome analysis of the oriental fruit fly (Bactrocera dorsalis). PLoS One. 2011;6:e29127.

72. Yong HS, Song SL, Lim PE, Eamsobhana P, Suana IW. Complete mitochondrial genome of three Bactrocera fruit flies of subgenus Bactrocera (Diptera: Tephritidae) and their phylogenetic implications. PLoS One. 2016;11(2):e0148201.

73. Steck GJ, Sheppard WS. Mitochondrial DNA variation in Anastrepha fraterculus. In: Aluja M, Liedo P, editors. Fruit Flies, Biology and Management. New York: Springer-Verlag; 1993. p. 9-14.

74. Alberti AC, Confalonieri VA, Zandomeni RO, Vilardi JC. Phylogeographic studies on natural populations of the south American fruit fly, Anastrepha fraterculus (Diptera: Tephritidae). Genetica. 2008;132:1-8.

75. Lanzavecchia SB, Juri M, Bonomi A, Gomulski L, Scannapieco AC, Segura DF, et al. Isolation and characterization of microsatellite markers from the South American fruit fly, Anastrepha fraterculus (Diptera: Tephritidae). BMC Genet. 2014;15(Suppl 2):S13.

76. Gilchrist AS, Cameron EC, Sved JA, Meats AW. Genetic consequences of domestication and mass rearing of pest fruit fly Bactrocera tryoni (Diptera: Tephritidae). J Econ Entomol. 2012;105:1051-6.

77. Zygouridis NE, Argov Y, Nemny-Lavy E, Augustinos AA, Nestel D, Mathiopoulos KD. Genetic changes during laboratory domestication of an olive fly SIT strain. J Appl Entomol. 2014;138:423-32.

78. Parreño MA, Scannapieco AC, Remis MI, Juri M, Vera MT, Segura DF, et al. Dynamics of genetic variability in Anastrepha fraterculus (Diptera: Tephritidae) during adaptation to laboratory rearing conditions. BMC Genet. 2014;15(Suppl 2):S14.

79. Vera MT, Abraham S, Oviedo A, Willink E. Demographic and quality control parameters of Anastrepha fraterculus (Diptera: Tephritidae) artificial rearing. Fla Entomol. 2007:90:53-7.

80. Jaldo HE, Willink E, Liedo P. Demographic analysis of mass-reared Anastrepha fraterculus (Diptera: Tephritidae) in Tucumán, Argentina. Rev Ind Agríc Tucumán. 2007:84:15-20.

81. Jaldo HE, Gramajo MC, Willink E. Mass rearing of Anastrepha fraterculus (Diptera: Tephritidae): a preliminary strategy. Fla Entomol. 2001;84:716.

82. Andrews S. FastQC: a quality control tool for high throughput sequence data. Available online at: http://www.bioinformatics.babraham.ac.uk/projects/fastac, 2010.

83. Bolger AM, Lohse M, Usadel B. Trimmomatic. A flexible trimmer for Illumina sequence data. Bioinformatics. 2014:30:2114-20.

84. Magoc T, Salzberg S. FLASH: fast length adjustment of short reads to improve genome assemblies. Bioinformatics. 2011;27(21):2957-63.

85. Grabherr MG, Haas BJ, Yassour M, Levin JZ, Thompson DA, Amit I, et al. Fulllength transcriptome assembly from RNA-Seq data without a reference genome. Nat Biotechnol. 2011;29:644-52.

86. SimãoFgo RM. Waterhouse, Panagiotis loannidis, Evgenia V. Kriventseva, Evgeny M. Zdobnov, BUSCO: assessing genome assembly and annotation completeness with single-copy orthologs. Bioinformatics. 2015;31:3210-2

87. Camacho C, Coulouris G, Avagyan V, Ma N, Papadopoulos J, Bealer K, Madden TL. BLAST+: architecture and applications. BMC Bioinformatics. 2009;10:421.

88. Götz S, García-Gómez JM, Terol J, Williams TD, Nagaraj SH, Nueda MJ, et al. High-throughput functional annotation and data mining with the BLAST2GO suite. Nucleic Acids Res. 2008:36:3420-35.

89. Langmead B, Salzberg S. Fast gapped-read alignment with bowtie 2. Nat Methods. 2012;9:357-9.

90. Roberts A, Pachter L. Streaming fragment assignment for real-time analysis of sequencing experiments. Nat Methods. 2013;10(1):71-3.

91. Pfaffl MW, Tichopad A, Prgomet C, Neuvians TP. Determination of stable housekeeping genes, differentially regulated target genes and sample integrity: BestKeeper--Excel-based tool using pair-wise correlations. Biotechnol Lett. 2004;26:509-15.

92. Pfaffl MW. A new mathematical model for relative quantification in real-time RT-PCR. Nucleic Acids Res. 2001;29:e45.

93. Hellemans J, Mortier G, De Paepe A, Speleman F, Vandesompele J. qBase relative quantification framework and software for management and automated analysis of real-time quantitative PCR data. Genome Biol. 2007:8:R19.

\section{Publisher's Note}

Springer Nature remains neutral with regard to jurisdictional claims in published maps and institutional affiliations. 